Noticias

\section{FEBRE AMARELA}

\section{Novas técnicas contra}

uma antiga ameaça

A febre amarela é uma velha conhecida. Provavelmente vinda da África, o primeiro registro de epidemia da doença em terras brasileiras foi em Pernambuco em 1685 , em um surto que também atingiu a Bahia. Entre 1980 e 2016, houve uma média de 22 casos e 11 mortes por ano no Brasil; enquanto que, em anos de pico, a média sobe para 52 casos e 21 óbitos. A alta mortalidade, de 40 a $50 \%$, possivelmente é um artefato da subnotificação; muitos casos são assintomáticos ou produzem apenas uma febre branda, confundida por várias doenças. Estima-se que a mortalidade da febre amarela seja em torno de $10 \%$; enquanto que, na forma grave, onde ocorre insuficiência renal e hepática e hemorragia, a mortalidade é de $50 \%$. Os casos da doença têm sido exclusivamente por contaminação com o vetor silvestre, precedidos por mortalidade de macacos em matas próximas a regiões rurais. De 2010 a 2016, a média anual de apenas 3,4 casos e 1,9 morte apontava para um cenário de controle da doença. Entretanto, no início de 2017, configurou-se

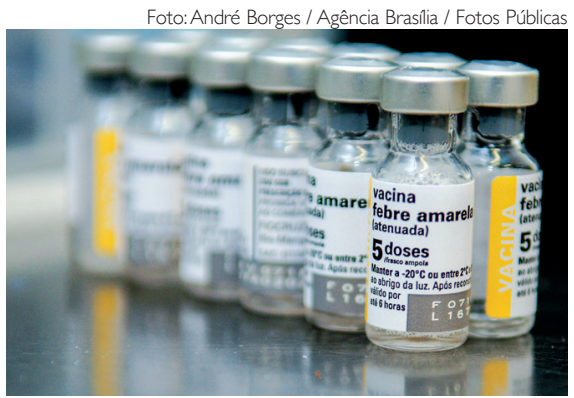

Falha em cobertura vacinal pode ter provocado surto de febre amarela

o maior surto de febre amarela desde o início da série histórica: 326 casos confirmados com 105 óbitos até fevereiro deste ano. 0 que teria provocado esse súbito aumento?

Talvez uma falha na cobertura vacinal nas localidades atingidas no estado de Minas Gerais: "Mais de $50 \%$ da população daquela área não tinha recebido a vacina", informa Pedro Tauil, infectologista da Universidade de Brasília (UnB). 0 presidente da Sociedade Brasileira de Virologia, Mauricio Nogueira, concorda: “O próprio Ministério da Saúde já havia previsto a expansão da febre amarela quando da ampliação da área de recomendação vacinal para o leste mineiro; porém esta recomendação não foi acompanhada de uma vacinação em larga escala da população exposta e aí sim está a grande falha". Nogueira prossegue: "Esta população não estava orientada, não tinha a memória cultural da febre amarela". Por isso: "A população e os serviços de saúde de Minas Gerais não associaram a morte de macacos com a febre amarela e os primeiros casos humanos demoraram para ser identificados", afirma. 0 problema, para Tauil, está na precariedade da infraestrutura dos municípios. “Não conheço nenhum município nessa área, por exemplo, que tenha equipes móveis de vacinação para atender a população mais vulnerável", diz.

\section{DESEQUILÍBRIO AMBIENTAL Já}

Fernando Portela Câmara, epidemiologista da Universidade Federal do Rio de Janeiro (UFRJ), acredita que fatores climáticos colaboraram para a aumentar a intensidade do surto. Ele destaca ainda a possibilidade de $o$ desequilíbrio ambiental causado pelo rompimento da barragem da mineradora Samarco/Vale-BHP na região de Mariana, em novembro de 2015, ter contribuído: “há uma forte suspeita de que esse desastre tenha forçado a fuga de muitos animais para essas regiões de transição", aponta. Macacos infectados teriam se deslocado para áreas de franja. Ao circularem entre os macacos e áreas habitadas por seres humanos, mosquitos transmitiram a doença para trabalhadores rurais e turistas. "É provável, mas isto não está provado", ressalva. Nem 


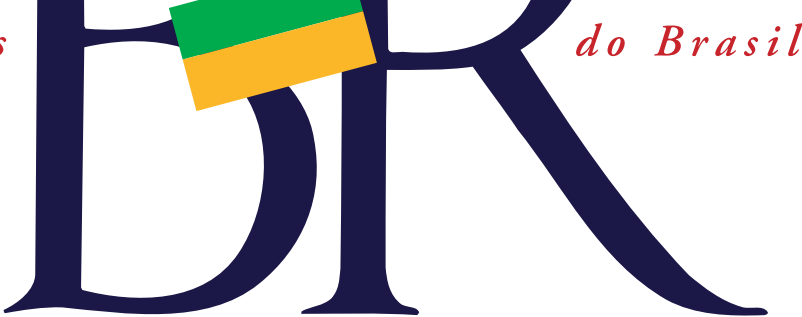

todos concordam. "A região onde estão ocorrendo os casos não é tão próxima assim a Mariana", contesta Nogueira. "Mesmo que aumentasse a população de mosquito - e isso pode ter acontecido - o desastre diminuiu a população de primatas não humanos na região", completa. Uma equipe do Instituto Adolfo Lutz, coordenada pelo virologista Renato Pereira de Souza, concluiu que o genoma do vírus detectado na região norte de São Paulo é muito similar ao vírus em circulação na região amazônica. Ele acredita que os vírus na região de Minas Gerais e Espírito Santo

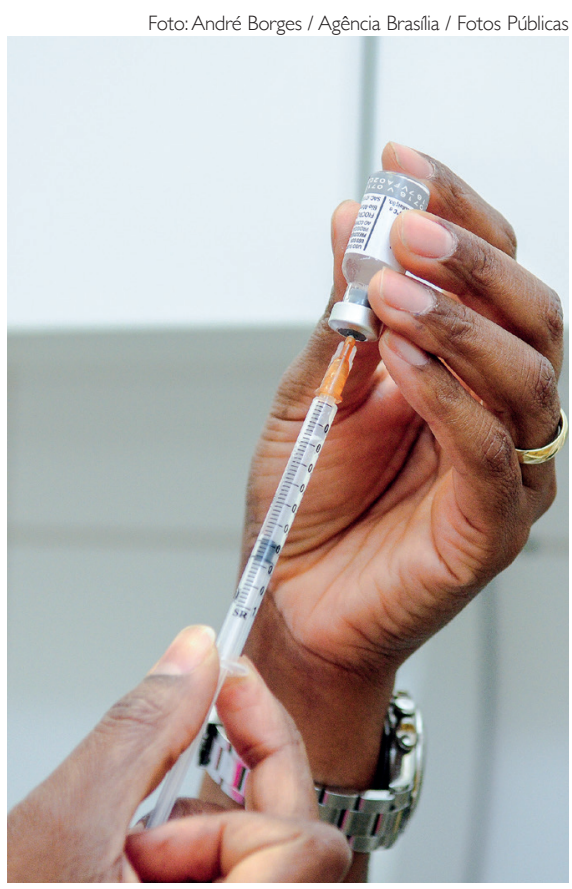

Institutos de pesquisa brasileiros investigam novas formulações de vacina para a doença sejam da mesma linhagem. "No entanto, testes adicionais podem indicar a contribuição de outras linhagens, mas isso está ainda a ser verificado", afirma Souza. Mas, se os vírus circulam a grandes distâncias, por que os padrões em surtos, em vez de uma taxa contínua de casos? "Uma das teorias mais em voga seria a disponibilidade de primatas não humanos susceptíveis para manter a circulação enzoótica em determinada região", explica Souza. Isto é, haveria um período de latência até a recuperação da população de macacos mortos pela febre amarela.

Em 2014, o Laboratório Nacional de Computação Científica, em parceria com a Fiocruz, lançou uma plataforma online de monitoramento da fauna e zoonoses, o Sistema de Informação em Saúde Silvestre (SISS-Geo: http://sissgeo.Incc. $\mathrm{br} /$ ). Colaboradores fornecem informações sobre comportamentos atípicos de diversos animais, o que permite gerar alertas antes de alastramento de doenças, inclusive a febre amarela. Porém, conforme conta Pereira, questões básicas sobre como os vírus realmente são levados a longas distâncias ainda precisam ser resolvidas, como quem efetivamente realiza esse transporte e quais são os parâmetros que precisamos medir para compreender 0 fenômeno. Ele cita também a necessidade de integrar não apenas epidemiologistas e virologistas, mas também entomólogos, primatólogos e climatologistas para responder qual o papel exato dos primatas e da fragmentação ambiental na circulação do vírus amarílico.

INOVAÇÕES Várias linhas de pesquisa vêm sendo desenvolvidas sobre a febre amarela. Uma delas tem como foco novas vacinas. A atual, desenvolvida em 1937, é considerada segura e eficiente, no entanto, ocorrem reações adversas, ainda que a uma taxa baixa. Nesses oitenta anos, aperfeiçoamentos foram introduzidos na vacina desenvolvida originalmente por pesquisadores da Fundação Rockfeller e produzida no Brasil, pelo Instituto de Tecnologia em Imunobiológicos (Bio-Manguinhos), da Fundação Oswaldo Cruz (Fiocruz). Duas inovações foram a introdução de ovos SPF (livre de patógenos específicos, na sigla em inglês), evitando a contaminação da vacina por outros agentes infecciosos durante a multiplicação do vírus amarílico nos embriões de galinha, e de substâncias estabilizadoras que permitem estocagem da vacina por um prazo maior. Atualmente, a Bio-Manguinhos pesquisa o desenvolvimento de vacina com 
Noticias

vírus mortos ou com partes dos vírus, a fim de evitar a replicação viral nas pessoas vacinadas: a formulação atual inclui vírus atenuados responsáveis pela maioria das reações adversas. Uma outra linha de investigação na Fiocruz consiste na liberação de mosquitos Aedes aegypti contaminados com a bactéria Wolbachia nos quais os vírus não conseguem atravessar a parede do intestino e seguir até as glândulas salivares. "Com isso, é possível conviver com os mosquitos sem que eles transmitam a febre amarela e outras arboviroses como a zika, chicungunha e dengue", explica Tauil.

Como no Brasil, no ciclo urbano da doença, o Aedes é o único transmissor, a febre amarela fica restrita à forma silvestre, transmitida por mosquitos de copas de árvores do gênero Sabethes e Haemogogus. Em projeto piloto em bairros das cidades do Rio de Janeiro e Niterói, houve substituição de até $80 \%$ da população de mosquito sem a bactéria por insetos com a Wolbachia. 0 próximo passo é estudar o impacto epidemiológico, isto é, se haverá redução da incidência de arboviroses. Atualmente, o tratamento dos pacientes acometidos pela febre amarela é apenas sintomático, no entanto, remédios mais específicos estão sendo pesquisados. De acordo com André Siqueira, infectologista do Instituto Nacional de Infectologia Evandro Chagas, há estudos com antivirais ou para desenvolver medicamentos que modulam a resposta inflamatória. "No entanto, apesar de mostrarem ação em modelos experimentais, não foram feitos estudos em pessoas infectadas", diz. Além das pesquisas com novos medicamentos, 0 infectologista acredita que seja necessário o desenvolvimento de testes sorológicos mais eficientes: “Os testes rápidos, que dispensem técnicas laboratoriais trabalhosas, apresentam grandes vantagens para o manejo adequado dos casos".

DEVER DE CASA As inovações e novos conhecimentos certamente ajudarão no enfrentamento da doença no futuro próximo. Porém, Pedro Tauil destaca: “É uma doença evitável por meio de um instrumento muito eficaz e bastante seguro, a vacina. Ela deve ser aplicada não só nas épocas de crise, mas deve estar na rotina vacinal de toda população exposta ao risco de adquirir a doença, das pessoas que vivem ou se deslocam para as áreas rurais onde há circulação do vírus entre macacos e alguns outros animais", finaliza.

Roberto Takata

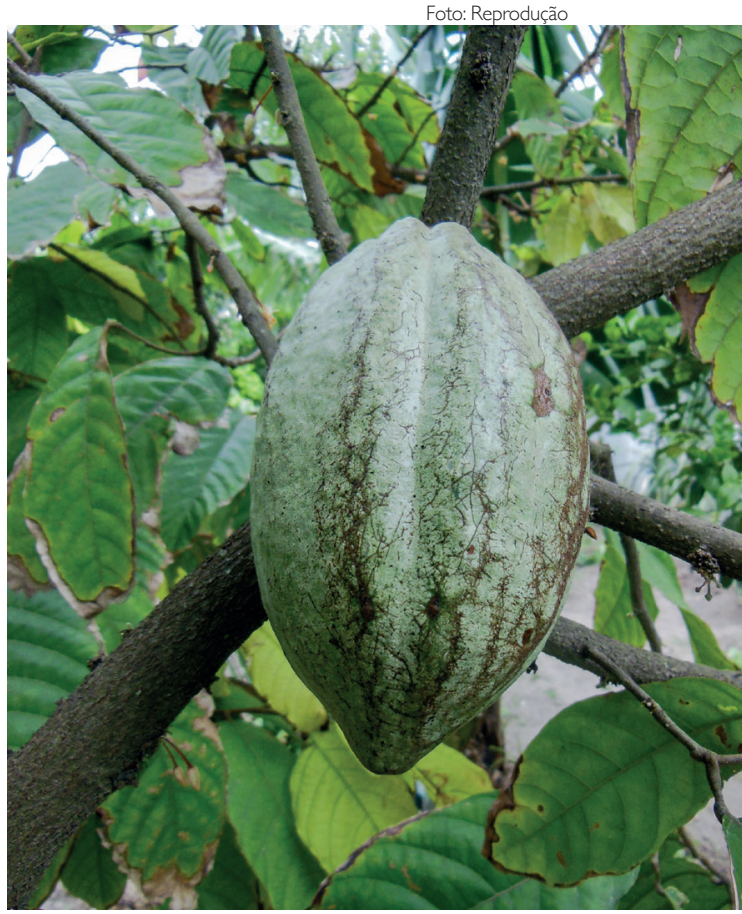

Cacau já foi um dos principais produtos da cesta de exportação brasileira

CACAU NO BRASIL

\section{Uma oportunidade que (ainda) não se concretizou}

De um dos maiores produtores e exportadores de cacau do mundo, hoje o país ocupa o quinto lugar, tendo que importar o fruto para suprir a produção nacional de chocolate. No entanto, nos últimos anos, pesquisas para melhoramento das sementes sinalizam para a recuperação da produção nacional. 